\title{
APPLICATION OF BIM TECHNOLOGY IN DESIGN AND CONSTRUCTION: A CASE STUDY OF PHARMACEUTICAL INDUSTRIAL BASE OF AMINO ACID BUILDING PROJECT
}

\author{
Lancine Doumbouya ${ }^{1}$, Chang Sheng Guan ${ }^{1}$, Guoping Gao ${ }^{1}$, Yangshao Pan ${ }^{2}$ \\ ${ }^{1}$ Wuhan University of Technology P.R. China; ${ }^{2}$ Tsinghua University, P.R. China \\ doumbouyala85@yahoo.fr,guancs2008@126.com
}

\begin{abstract}
The rapid development of information technology has brought several innovations to the field of civil engineering. BIM (Building Information Modeling) technology places emphasis on information integration and the establishment of a database. It also aims to realize the building life-cycle management. BIM technology is exerting a significant and profound impact on the design, construction, management, operation, and maintenance of building projects. In this study, the value of BIM in construction projects was analyzed, and the significant meaning of this study was elaborated. BIM standards and the data standard of IFC were discussed, and the important concepts of 4D-BIM and 5D-BIM were also presented. The key technologies like parameterization, visualization, geographic information system, building life cycle management, and clouding computing were analyzed. Furthermore, the mechanical behaviour of the building was analyzed, and the value of BIM in construction was expounded. Particularly, the application of BIM in bidding, BIM virtual construction, clash detection, and refined calculation about resources as well as materials were analyzed in this paper. Also, the construction dynamical management system of 4D-BIM was discussed. Finally, the coordination, which acts as an important issue between the BIM design and BIM construction, were analyzed comprehensively.
\end{abstract}

Keywords: BIM technology; design construction; simulation; schedule; building.

\section{Introduction}

The 21st century marks the advancement of technology, the era of rapid development of information technology, and the building information modeling (BIM, Building Information Modeling). As a building project in the field of a new technology, BIM is not only the product of the birth of the information age. However, it has brought about social productivity and has met urgent developmental needs. Through external factors such as Locations and local design conditions, BIM will form the architectural design of intelligent 2D and 3D object, which is connected to a virtual building in a database. Therefore, the database is associated with certain buildings, single, integrated, and covers all building information source [1].

BIM's integrated data information covers all phases of the building lifecycle, including the planning phase, design phase, construction phase, operation and maintenance phase, predictive control stages, etc. [2; 3]. BIM is often likened to the DNA of a building [4]. Throughout the design process, especially in the early architectural design, more detailed data information has been included, since the construction industry has become a growing trend [5].

BIM is an important architectural design process, which is used to meet the requirement of the data. This requirement is the building information model to show a unified description of a building. Consequently, BIM can greatly enhance the design, construction, and building lifecycle of information flow in various stages. Thus, these include the building lifecycle, architects, equipment engineers, contractors, and owners. The use of Virtual Building BIM has created an important advantage that spaces constraints in the construction of the project, and which the virtual construction equipment engineers can help in optimizing the arrangement of HVAC systems [6].

BIM can virtually build an HVAC system and virtual collision detection in a three-dimensional environment [7]. BIM can improve the accuracy of cost evaluation because the information provided by BIM has a certain depth and accuracy. Therefore, extracting materials and the number of consumption becomes relatively easy and quick. Also, cost evaluation improves its speed and accuracy. BIM system is used to better measure the impact of design changes, which can be used to automatically handle budget problems [8]. It helps improve the accuracy of energy analysis; used to calculate the energy consumption despite the need for additional software tools; and is used for energy analysis of the data stored in the BIM model [9]. 


\section{Research Background and Significance of the Study}

\subsection{Research Background of Gorges Pharmaceutical Amino Industrial Base}

It has a building area $4807 \mathrm{~m}^{2}$, building height $24.5 \mathrm{~m}$, building layers (local five), reinforced concrete frame structure, reasonable service life of 50 years, and a seismic intensity of 6 degrees. The project BIM application contents include: the establishment of a civil construction BIM model, building outward appearances, windows table, material tables, BIM structure model structural analysis, structural analysis of various data, schedule cost model, the hierarchical discharge table, time tables, and other data. The established BIM model based on construction drawings includes: build three-dimensional model paper size doors and windows, i.e. the hole, location, and size basis. Entry drawing information includes: wall construction materials and decoration materials such as doors and windows of the type, size, material, roofing materials, and other information. In addition, it involves the adjustment of the building exterior colour and look to fill styles.

\subsection{Significance of the Study}

The use of the BIM technology in construction projects will undoubtedly bring about a revolution to the construction industry. BIM is a new technology. It is currently being used in foreign countries, especially in developed regions. In China, the use of the BIM technology just started. This paper focuses on the application of BIM in the design phase and construction phase. In addition, the BIM coordination between these two stages was studied. Throughout this study, the significance of the research points is summed as follows:

1) Theory. The problem in the study summed up the tools needed to implement BIM. This is achieved through access to information and deep thinking, function of the key technology for BIM and the corresponding technology has been further elaborated and summarized; studied BIM to achieve information interoperability, data sharing and transformation, cloud services, predictive control and coordination of the design and construction of other issues, of which such work is to further study the theory of BIM knowledge; mathematical prediction model proposed in this paper, design and construction of computer-aided assessment, which further explore the theory of BIM; and finally research and coordination on construction issues from the BIM theory, on the one hand, and the problem of coordination the BIM theory which has deepened, on the other hand.

2) Real Practical Significance. The problem of the study involves having an accumulated practical experience and know-how on how to use the BIM software tools. The BIM parametric design and its visualization can be achieved. Also, virtual construction and construction schedule management of BIM is able to be practiced successfully [10]. In the study of the BIM design and construction, how to coordinate the design and construction in BIM environment were also studied. Therefore, this work experience is usually provided after the application of BIM. In addition, the promotion and application of BIM have a realistic significance.

\section{Research Methodology}

The research methodology is faced with the rapid development of the BIM technology and application of China's construction industry and the problems that exist particularly in engineering practice. How to select the right one is worth studying. However, this is done with reference to the direction of the meaning and practice tests, which has become a part of this article's critical thinking. The core of this paper includes the design and construction of the project implementation process in two important stages, how to effectively use the BIM technology in these two important stages, and how to maintain the BIM technology in the design and construction coordination $[11 ; 12]$. An innovative mathematical model is proposed to introduce BIM model. This model, however, constitutes of thinking of BIM model predictive control. Therefore, the BIM technology will be applied to practical engineering problems. This is done through hands-on for the purpose of learning and experiencing the BIM technology in design and construction so as to test the theoretical methods. The 4D-BIM is used in construction simulation on the 5D-BIM coordination problems with the design and construction. 


\subsection{BIM Engineering Model Predictive Control Problem}

$\mathrm{BIM}$ requires the use of specific data and it also requires a mathematical model, which is instantiated and parameterized. In BIM, due to the fact that technology is becoming increasingly important in the control of energy consumption, material consumption, labor and machinery allocation, time schedule, equipment, and resource management, the use of predictive models has become very meaningful [13]. When the predictions forecasting model is not conducive, the BIM project proceeds. The various factors that influence the project would need to be adjusted in a timely manner. When the forecasting model is predicted, BIM facilitates the project execution. In addition, we can also optimize all influencing factors in order to achieve optimal control project. Real-world use and performance data are required. The purpose is to accurately assess the performance of the design and to improve the predictive models. However, logical analysis chart of BIM model predictive control is shown in Fig 1 below:

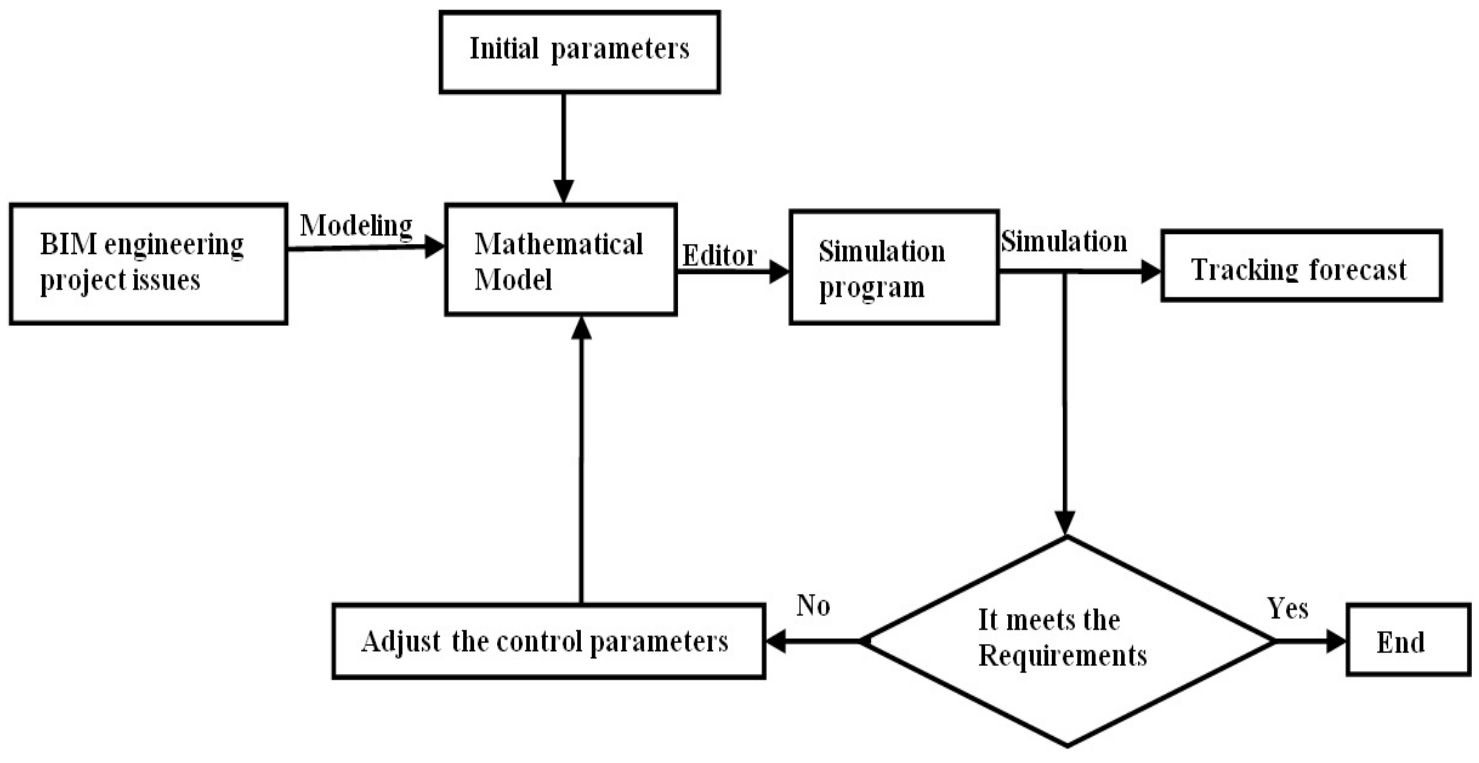

Fig. 1. Logical analysis chart of BIM model predictive control

\subsection{BIM Duration of the Pre-schedule and BIM Progress of Construction Period Prediction Model}

Faced with a variety of project problems, the forecasting model based on the BIM technology is complex and diverse. Here, progress is based on the duration prediction of the research questions. Many factors affect the progress of the construction of the project, and it has different classification methods. To sum up, a combination of factors includes human, material supply, finances, design changes, and other risk factors [14].

Paragraph $i$ influence factors $X_{i}$ state values are represented by $x_{i}(1 \leq i \leq n)$. They constitute a factor of the vector given as $\vec{x}=\left(x_{1}, x_{2}, \ldots, x_{n}\right)$. Therefore, the target duration $T_{M}$ and the forecast period $T_{Y}$ can be expressed as follows:

$$
\begin{aligned}
T_{M} & =T_{M}(\vec{x}), \\
T_{Y} & =T_{Y}(\vec{x}) .
\end{aligned}
$$

There is a special case. In this case, the target period is constant, that is:

$$
T_{M}=T_{M}(\vec{x})=\text { const }=T_{M}\left(\overrightarrow{x_{o}}\right),
$$

Remember, $\vec{x}=\vec{x}_{o}$ when the construction schedule of the target duration $T_{M}$ fetches

$$
\overrightarrow{x_{o}}=\overbrace{(0,0, \ldots, 0)}^{n \text {-dim }} \text {. }
$$


- Mathematical models which predict the duration can be expressed as follows:

$$
T_{Y}(\vec{x})=T_{M}\left(\overrightarrow{x_{o}}\right)+\left\|\vec{x}-\overrightarrow{x_{o}}\right\| T_{M}\left(\overrightarrow{x_{o}}\right),
$$

where $\left\|\vec{x}-\vec{x}_{o}\right\|$ is of a particular measure.

Therefore, you can use $\varepsilon(\vec{x})$ to express this measure. Thus, the forecast period schedule model can be expressed as:

$$
T_{Y}(\vec{x})=T_{M}+\varepsilon(\vec{x}) T_{M}=(1+\varepsilon(\vec{x})) T_{M} .
$$

Prediction Model of the progress of the construction period Eqn (5) for the project shows that the problem is multifaceted [15]. However, this can be a single factor. Also, the duration of the schedule under the effect of several factors to predict can also be uncertain factors. These factors not only predict the randomness situation, but also predict the work unit, critical path, and the overall construction of the network progress forecast period. Through computer programming, the prediction model and BIM model architecture form BIM model predictive control schedule progress [16].

\section{Cases Study Overview}

- Computational Analysis

This section is mainly based on the theory of BIM above the Three Gorges Pharmaceutical amino acid industry base construction projects, which was constructed using modeling and structural modeling. In building the model, you can use the parameters of BIM and visualization to feel and understand the look and feel of the building. Also, it can be used to change the different perspectives in the building information model in order to observe the exterior of the building. In the structural model, the analysis of the mechanical behaviour of the housing structure under load includes: the axial force, shear, moment, torque, etc. Consequently, there are support reactions, stress structure analysis, structural nodal displacements under load analysis, and node reaction analysis by the force of the lever; hence, this is with BIM software export which forms data that strengthen the theory [1].

\subsection{BIM in Architectural Design}

Three Gorges Project Pharmaceutical amino acid industry base building design was designed using Revit Architecture software.

The BIM technology described above is actually used in the parametric design. Revit threedimensional visualization can be used to observe the plant building plans, which have been established. Gorges Pharmaceutical amino industrial base, which has an overall architectural appearance, is shown in Fig. 2 a). Changing the angle of the view of the entire building can be observed in Fig. 2 b), respectively. However, it is the conventional two-dimensional CAD Graphic design, which cannot be achieved.
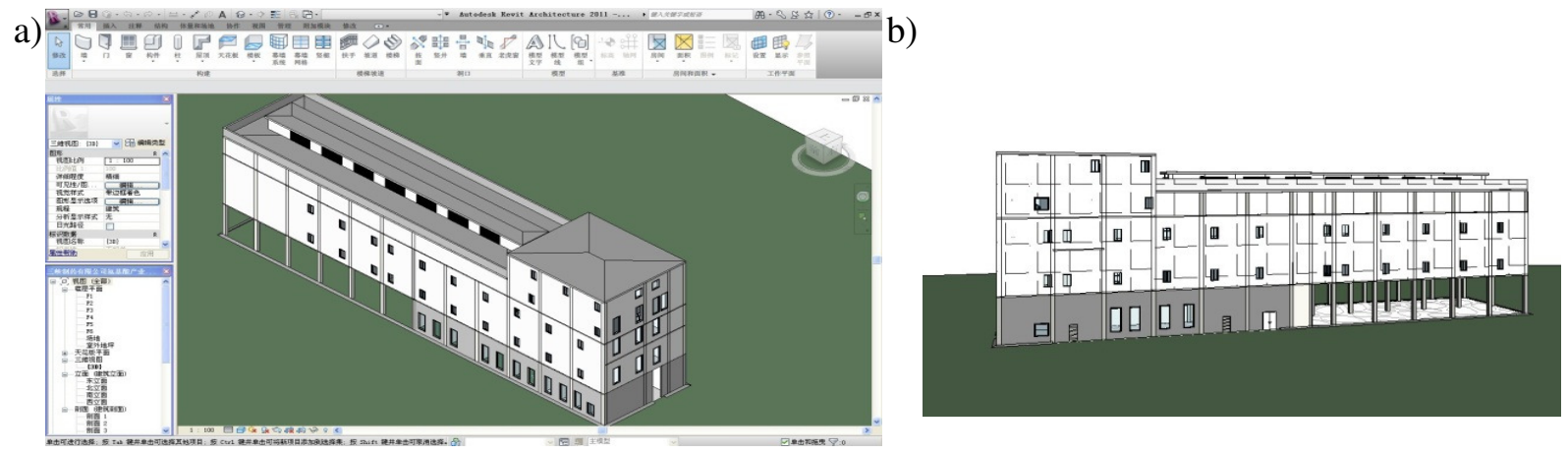

Fig. 2. BIM model views the whole building (a); BIM building view different perspectives (b)

After the completion of the building of the BIM design, based on the building model of the project, the schedule design was obtained. In the list, which displays the drawing information in a tabular form, the information is extracted from the project element properties. 


\subsection{Results of BIM Applications in Structural Design}

The BIM structure model for this project uses Revit Structure (RST) software to achieve the establishment of the BIM structure model for the structure of construction drawings, and threedimensional structural model that is set up according to the size of the drawing beams and columns, location, layout, and so on [5]. RST frame beam, as defined by the software, can be similarly drawn on methods of the previously defined column, that is, by means of the concept of "family" to be defined.

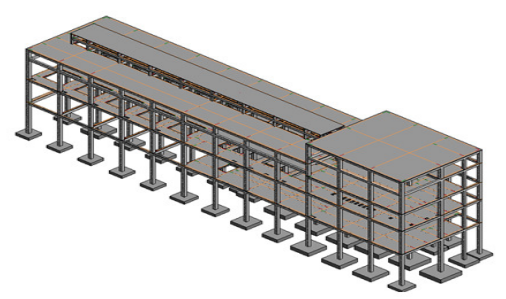

\section{Fig. 3. Model for the overall structure - BIM structural model}

First, it is done through the grids of the beam positioning. Then, the pair of beams is arranged not only to define the starting point of the elevation, but also the end point of the elevation beam. Here, it is used to conduct independent foundation under the column layout. On the basis of the structural model, the analysis model was modified and amended at the end. It was introduced into the analytical software robot, the boundary conditions, and the load information. Afterward, it was added up to the mechanical behaviour of the structure calculation and analysis. On the basis of the constitutive models, plus loads, we get a physical model of the structure shown in Fig. 5.

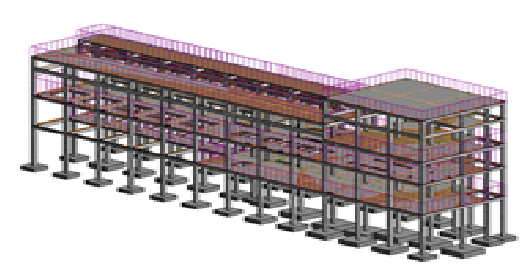

Fig. 4. Physical model structure

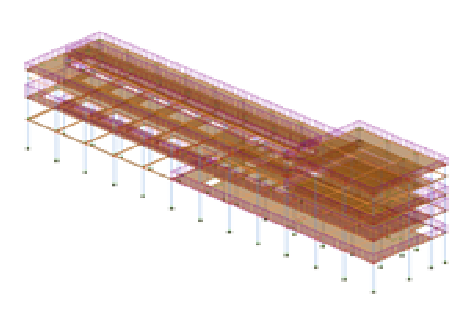

Fig. 5. Adjusted structural model

\subsection{Mechanical behavior analysis of the structure of the second plant}

After the completion of its structural modeling workshop, there is the need to analyze the mechanical behaviour of the plant structure. This is most commonly and widely recognized as a software Robot. Adjusted in accordance with the structural analysis model, the structural adjustment model is introduced after completion of Revit Robot software. Then, it adds to the boundary conditions, load information, and performs structural stress analysis calculations. Once it has been imported, the structure of the model becomes a finite element model after meshing, as shown in Fig 7 below. BIM structural analysis software is used for finite element calculation of the plant structure. Calculation of the force structure, in broad terms, consists of three parts, namely: normal direction stress, shear stress, and torsional stress. However, the results of the structural analysis are to extract data: lever points to stress contours, contours axial force, normal stress contours, torsional shear stress contours, precise structure deformation maps, board section (Force-N: Moment-M: Shear stress$\mathrm{t}$ : Shear force Q: Plate section displacement-u, w: Corner-R: Ground reaction force-K) cloth cloud like. Due to the complexity of the analysis process, as well as a larger workload, the results will be part of the structure of plants on display inside this section. However, the specific content is shown in Fig. 6 a) to f) below. 
a)

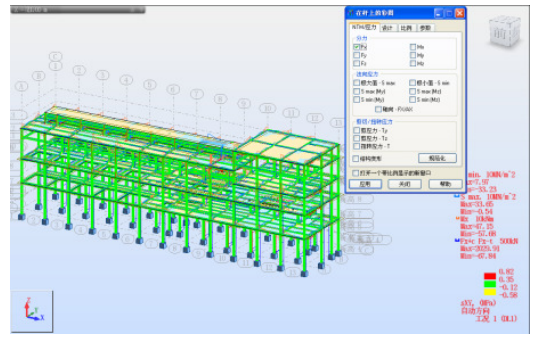

d)

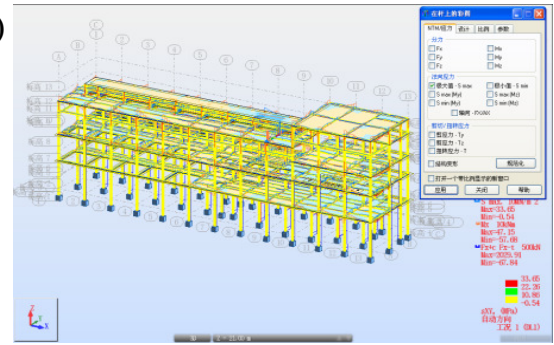

b)

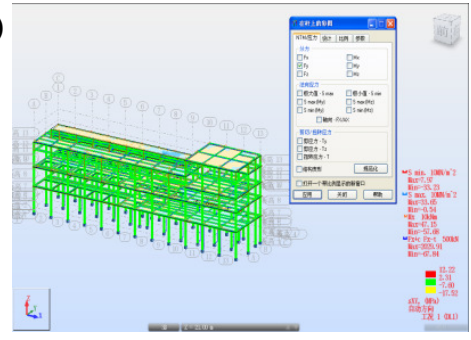

e)

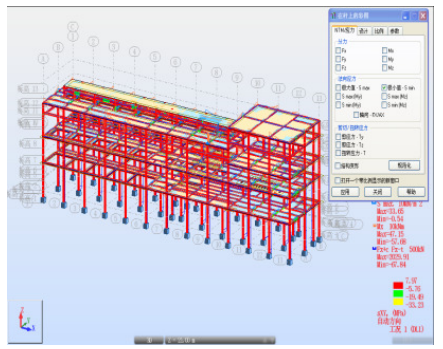

c)

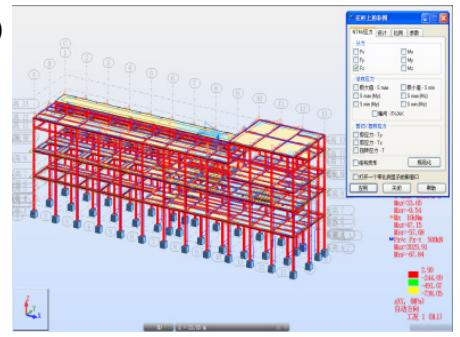

f)

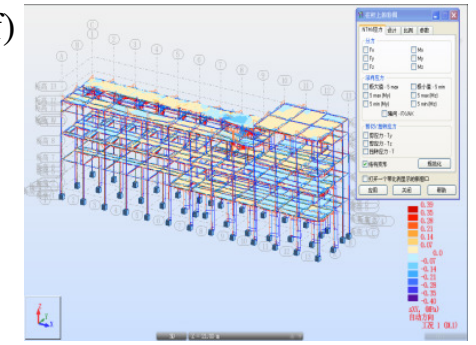

Fig. 6. Distribution powerhouse structure $\mathbf{X}$ direction of the force (a), distribution powerhouse structure $Y$ direction of the force (b), distribution powerhouse structure $Z$ direction of the force (c), stress maximal distribution plant construction law (d), stress minimal value distribution plant construction law (e) and torsion stress distribution plant (f)

\section{Case simulation and results for the virtual construction of the plant}

In the pharmaceutical rooms inside this building, there are a number of units for industrial use of the amino acid fermentation tank in the model of the device; hence, you need to use BIM software in the professional family file $[17 ; 18]$. This section of the factory buildings during construction of a reinforced concrete frame structure is a virtual construction study of BIM [19-22]. For this project case, the virtual construction process is roughly divided into the following steps: firstly, it was based on the amino acid Gorges Pharmaceutical industrial base plane drawing, according to the actual size of the completed building modelling workshop in the professional Revit Architecture BIM software. Secondly, it was based on the Revit Structure software inside. This is completed in accordance with the actual size of this building structure modelling workshop. According to the above analysis and simulation steps, the virtual construction of the Three Gorges Pharmaceutical plant amino acid industrial base is shown in the figures below:

a)

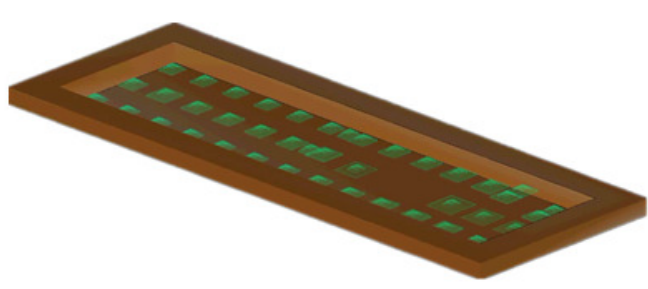

i)

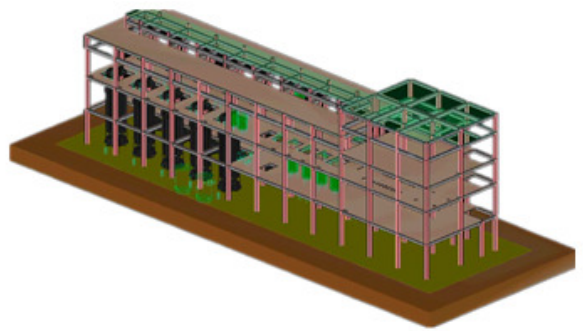

b)

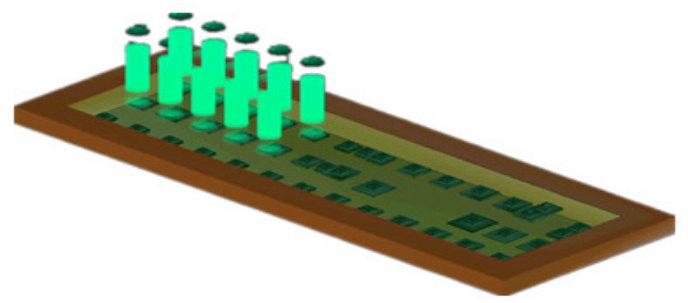

j)

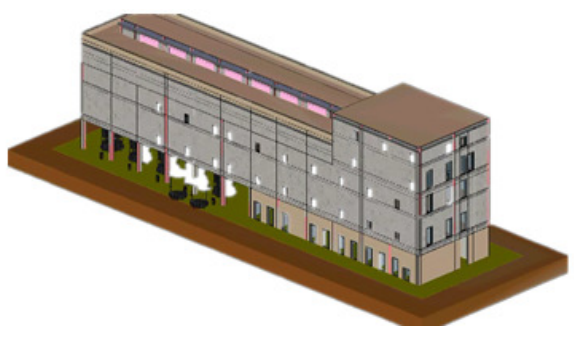

Fig. 7. Infrastructure construction plant (a), amino acid fermentation tank construction (b), fifth-floor slab plant construction (i), the entire facades plant construction (j)Coordination of Design and Construction Case Study 
Based on the concept of controlled 5D BIM coordination, design and construction coordination is not only in terms of the progress of the project, but is also reflected in the cost of the project [23]. This is carried out for a specific building project, in order to control the various stages of design and construction, and also to control the schedule and cost. Fig. 8 a) to Fig. 8 f) respectively is the BIM cost model. Hence, the details are as follows.
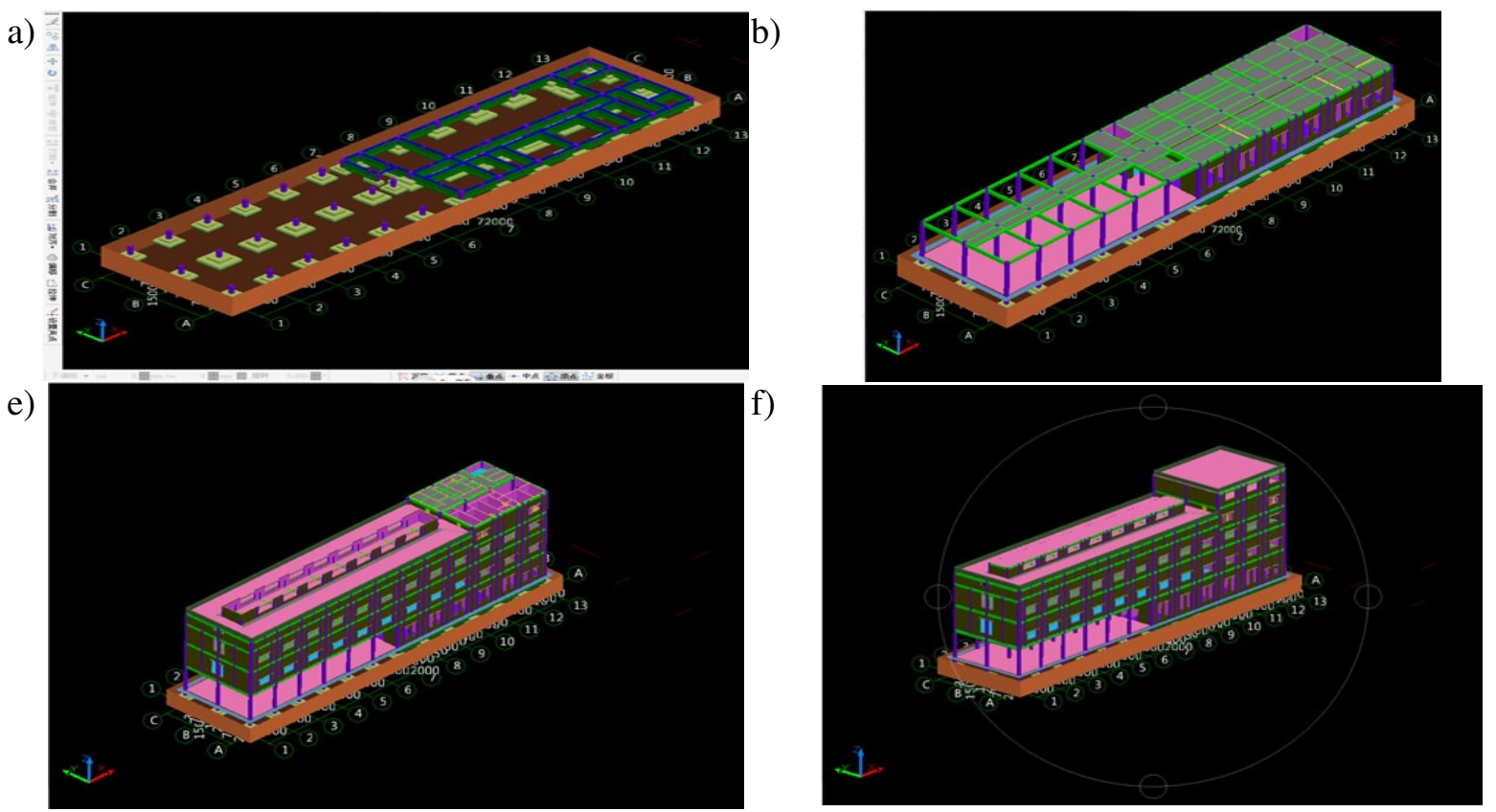

Fig. 8. Cost model basis (a), foundation -one cost model (b), basics - four cost model (e), Basics - five cost model (f)

\section{Conclusions}

Design and construction are two important parts of the construction industry. Thus, the conclusion of this article obtained in the research process is multifaceted. The BIM technology in today's construction industry is a hot technology, but it also has very broad application prospects of technology. Although it has been relatively mature in foreign countries, China's BIM application has just started. Therefore, to further promote the application of BIM in China, there are many important research works worth learning. The BIM technology, visualization, parameterization, information, integration, sharing, controlling, simulation, coordination, flexibility, predictability, and other features have made the BIM technology in design and construction to become significant. The BIM technology in the construction and structural design applications has fully demonstrated its distinct advantages. The 3D parametric design has completely changed the way of thinking of conventional design. 4D BIM in construction brings tremendous value. Also, construction bidding using the BIM technology can significantly enhance the competitiveness of the bidders; thus, the virtual construction technology saves time and cost, and helps anticipate difficulties in construction, timely detection, and problemsolving. In collision detection, fine BIM computing resources is an important material used in construction coordination. However, the BIM design and construction issues are worth studying. In addition, 5D BIM is an important method for solving the design and construction coordination, which fully takes into account the progress and costs of the project, so as to coordinate the relationship between the design and construction.

\section{References}

1. Porwal A., Hewage K.N. Building Information Modeling (BIM) partnering framework for public construction projects," Automation in Construction, vol. 31, 2013, pp. 204-214.

2. Wang J., Zhang X., Shou W. et al. A BIM-based approach for automated tower crane layout planning, Automation in Construction, vol. 59, 2015, pp.168-178.

3. Assessing the Performance of the BIM Implementation Process within a Small Specialty Contracting Enterprise. [online][11.12.2016] Available at: 
http://smc06.manuscriptcentral.comcjce-pubs-28-May-2015.pdf

4. Eastman C. et al. BIM Handbook: A Guide to Building Information Modeling for Owners, Managers, Designers, Engineers, and Contractors.Copyright () 2008 John Wiley \& Sons, Inc.

5. Zhenzhong H., Jianping Z., Ziyin D. Construction Process Simulation and Safety Analysis Based on Building Information Model and 4D Technology[J].Tsinghua Scienceand Technology. ISSN:1007-0214, 43/67, Volume 13, Number S1, 2008, pp. 266-272.

6. Singh M.M., Sawhney A., Borrmann A. Modular Coordination and BIM: Development of Rule Based Smart Building Components, Procedia Engineering, Volume 123, 2015, pp. 519-527.

7. Jiao Y., Zhang S., Li Y. et al., Towards cloud Augmented Reality for construction application by BIM and SNS integration, Automation in Construction, vol. 33, 2013, pp. 37-47.

8. Zhang S., Sulankivi K., Kiviniemi M. et al. "BIM-based fall hazard identification and prevention in construction safety planning," Safety Science, vol. 72, 2015, pp. 31-45.

9. Goes R.H.T.B., Santos E.T. Design Coordination with Building Information Modelling: A Case Study, in CIB W78-W102 2011: International Conference, Sophia Antipolis, France, 2011.

10. Hartmann T., van Meerveld H. Vossebeld N. Adriaanse A. Aligning building information model tools and construction management methods[J]. Automation in Construction 22, 2012, pp. 605-613.

11. Khosrowshahi F., Arayici Y. Roadmap for implementation of BIM in the UK construction industry, Engineering, Construction and Architectural Management, vol. 19, no. 6, 2012, pp. 610-635.

12. Beth A. Brucker, Michael P. Case, et al. Building Information Modeling: A Road Map for Implementation to Support MILCON Transformation and Civil Works Projects within the U.S. Army Corps of Engineers, 2006.

13. Azhar S. Building Information Modeling (BIM): Trends,Benefits, Risks, andChallenges for theAEC Industry [J], Leadership and Management in Engineering, 2011.

14. Poirier E.A., Staub-French S., Forgues D. Assessing the performance of the building information modeling (BIM) implementation process within a small specialty contracting enterprise, Canadian Journal of Civil Engineering, 2015, 42(10), pp. 766-778.

15. Ginevičius R., Podvezko V. Multicriteria graphical-analytical evaluation of thefinancial state of construction enterprises, Technological and Economic Development of Economy 14 (4), 2008, pp. 452-461

16. Zhang S., Teizer J., Lee J.K., Eastman C.M., Venugopal M. Building Information Modeling (BIM) and Safety: Automatic Safety Checking ofConstruction Models and Schedules[J], Automation in Construction 29, 2013, pp. 183-195

17. Chen S.M., Griffis F.H., Chen P.H., Chang L.M. Simulation and analytical techniques for construction resource planningand scheduling [J]. Automation in Construction 21, 2012, pp. 99-113

18. König M., Koch C., Habenich I., Spieckermann S. Intelligent BIM-based Construction Scheduling Using Discrete Event Simulation, Proceedings of the 2012 Winter Simulation Conference.

19. Wetter M. A View on Future Building System Modeling and Simulation, Book chapter published in "Building Performance Simulation for Design and Operation," Jan L. M. Hensenand Roberto Lamberts (editors), Routledge, UK, 2011, ISBN: 978-0-415-47414-6.

20. Juszczyk M., Výskala M. Zima K. Prospects for the use of BIM in Poland and the Czech Republic - Preliminary Research Results, Procedia Engineering, vol. 123, 2015, pp. 250-259.

21. Guo H.L., L. H., and Skitmore M. Life cycle management of construction projects based on Virtual Prototyping technology [J]. Journal of Management in Engineering, 26(1), 2010, pp. 41-47

22. Qi J., Issa R.R.A., Hinze J., Olbina S. Integration of safety in design through the use of building information modeling, Proceedings of the 2011 ASCE International Workshop on Computing in Civil Engineering, 2011, pp. 698-705.

23. Popov V., Juocevicius V., Migilinskas D., Ustinovichius L., Mikalauskas S. The use of a virtual building design and construction model for developing aneffective project concept in 5D environment[J], Automation in Construction19, 2010, pp. 357-367. 